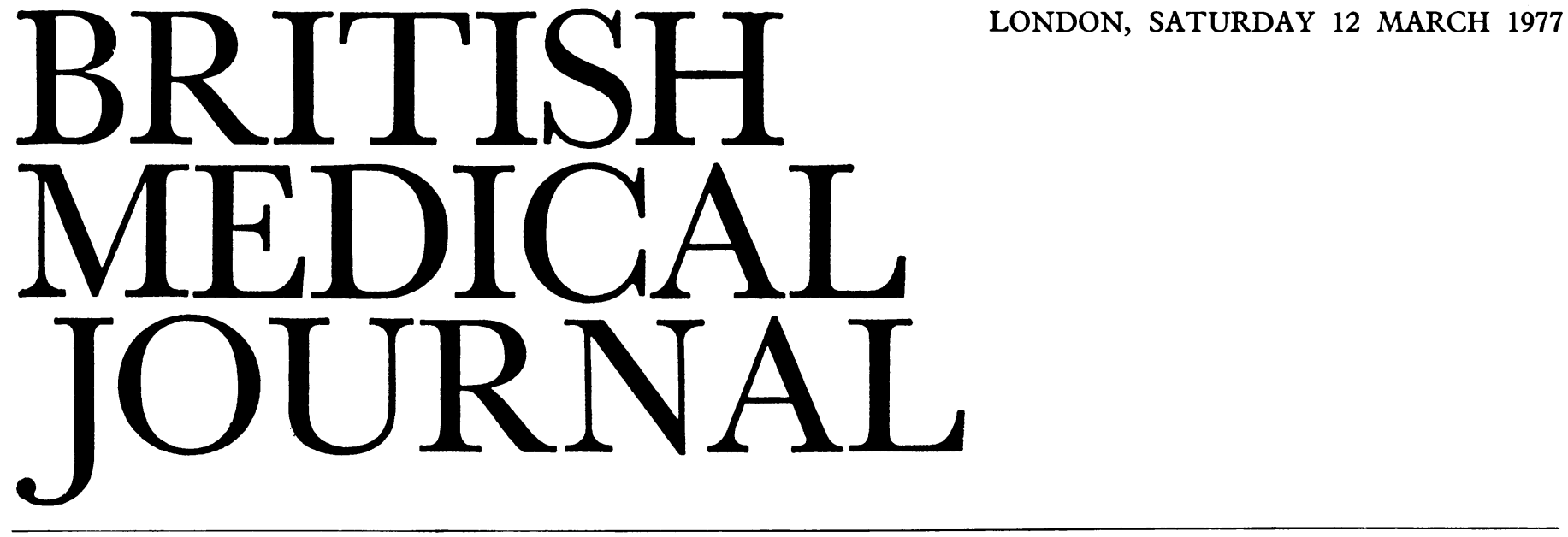

\title{
Action on alcohol and road accidents
}

In 1907 a leading article in the Lancet drew attention ${ }^{1}$ to the dangers of driving under the influence of alcohol "with the ever growing numbers of motor omnibuses hurtling through our streets" and remarked that "the appalling risks that may arise from the intoxication of an engine driver or chauffeur are too obvious to need mention." Seventy years later alcohol has become the most important single factor in determining risk of road accidents in most technically developed countries. At the Seventh International Conference on Alcohol, Drugs, and Traffic Safety, held at Melbourne earlier this year, very few countries reported any real progress in dealing with the problem. The most depressing development has been the shift downwards in the age at which alcohol is being abused by drivers-and in particular by men. In the year after the Road Safety Act of 1967 (which introduced in Britain a legal blood alcohol concentration limit of $80 \mathrm{mg} 100 \mathrm{ml}$ and screening breath tests) the proportion of drivers in the 20-40 age group killed in road accidents and found with an excess of alcohol fell from just under $40 \%$ to $20 \%$. By 1974 it had risen $^{2}$ to nearly $50 \%$. Road accidents now account for more than $40 \%$ of all male deaths between the ages of 15 and 24 in England and Wales. ${ }^{3}$ How long can public health authorities continue to ignore the problem as being within the responsibility of the authorities concerned with road safety?

The Melbourne conference showed very clearly that one of the main reasons for failure to control drinking drivers is their extremely small risk of being caught while driving with above the legal limit of alcohol. Professor H L Ross ${ }^{4}$ of Denver made a detailed analysis of casualty savings after the 1967 legislation and concluded that "the risk of apprehension for a drinking driver in Britain is realistically quite minute, and this fact is increasingly being learnt by the public, who are adjusting their behaviour in consequence." Awareness of this problem has led many countries to consider the introduction of what are wrongly termed "random tests" allowing a police officer to obtain a screening breath test from a driver entirely at the officer's discretion. The report of the Australian Law Reform Commission," which considered this approach in considerably more depth than our own Blennerhassett Committee, ${ }^{6}$ came out against such tests. The distribution of very high blood alcohol concentrations among the driving population is highly selective, and the introduction of random tests would not therefore be cost-effective.

This is the heart of the problem. The main contributor to alcohol-related crashes is not the average or typical drinking driver who inadvertently exceeds the limit: it is the atypical and exceptional driver who drinks very excessively. The mean blood alcohol concentration of drivers detained on a screening breath test is usually found to be at about two or three times the legal limit. ${ }^{7}$ The case for random tests should rest on distribution studies of alcohol in the driver population, and no such tests have yet been carried out in Britain. Meanwhile, the best hope lies in concentrating screening breath tests at those places where drivers are most likely to be found with above the legal limit, or, as Borkenstein ${ }^{8}$ suggests, where alcohol related accidents are most likely to occur. Thus the Blennerhassett recommendations reflect British domestic problems. Our magistrates' courts seem prepared to acquit drivers found with very high blood concentrations of alcohol on the fictitious grounds that the police officer might not have had any reason to believe that the driver had alcohol in his body at the time the screening breath test was requested. This behaviour by our courts left the committee very little option than to remove all legal restrictions placed on the police in requesting a breath test.

Next, the poor quality of data on road accident morbidity remains unique in public health practice. There is clearly a pressing need (not so far recognised in Britain) for information to be provided in confidence by hospitals about blood alcohol concentrations in victims of road accidents. The sampling of drivers by hospital doctors for medicolegal purposes is, however, a very different matter. If a duty were to be put on doctors concerned with the treatment of victims to take blood from every road accident victim, conscious or unconscious, to complete several forms, and to send the sample to the police for purposes of considering a criminal prosecution, that would represent an important departure from the accepted principles of medical ethics. Hardly surprisingly, the medical profession in New Zealand ${ }^{9}$ as well as in Victoria and South Australia resisted such legislation when it was recently introduced. Clearly hospitals must not provide a haven of refuge for the drinking driver, and the solution proposed by the BMA (and accepted by the British Government) appears to be preferable: a sample of blond is taken by a police surgeon unconnected with the treatment of the victim and then only with the permission of the doctor in charge of the case. ${ }^{10}$

There remains the question of what is to be done with the drinking driver. Solutions range from the controversial Swedish 
unconditional prison sentence to our own country, which almost invariably imposes disqualification from driving for one year without any inquiry into whether the offender has any symptoms of alcoholism. About $40 \%$ of all prison sentences in Sweden are passed on drinking drivers, who account for $10^{\circ} \%$ of the prison population ${ }^{11}$ : yet while that country is popularly believed to have achieved success with the drinking driver, independent investigation has found it no more successful than Britain or the United States. Our own failure to discriminate in sentencing policy between different types of drinking driver has had predictable results in the form of repeated convictions. The Blennerhassett Committee recommended that a group of high risk offenders should be identified and required to convince the courts that their driving no longer represents a danger to other road users. This highly practicable solution should surely be adopted as soon as possible.

Furthermore, the increase in the number of drivers who abuse alcohol and its consequences should stimulate the medical profession to review the reckless abandon with which it regards alcoholism. It is now 15 years since Glatt ${ }^{12}$ pointed out that a conviction for drinking driving is a remarkably constant early feature in the history of alcoholism, and a recent Irish survey has confirmed this, showing how often drivers admitted to hospitals with alcohol-related conditions were discharged without receiving any treatment for alcoholism and then went on to commit a drinking driving offence. The BMA evidence to the Blennerhassett Committee $^{6}$ recom- $^{-}$ mended a blood alcohol concentration of $150 \mathrm{mg} 100 \mathrm{ml}$ (at least twice the upper limit of ordinary social drinking) as the cut-off point for identifying high risk offenders. Yet even with the current very low rate of detection through breath testing, about 25000 drivers are convicted each year with concentrations above that level. It is likely that sheer weight of numbers combined with lack of adequate resources forced the committee to fix the cut-off level at $200 \mathrm{mg} / 100 \mathrm{ml}$, which would bring the number down to about 15000 . Priority must, then, be given to dealing with these very high risk group drivers with alcohol concentrations which ordinary drivers would never reach without unpleasant symptoms of intoxication.

There remains, finally, the controversial issue of what we should tell the driving population as a whole. There are two practical difficulties. In the first place the individual risk of accident at different concentrations varies considerably. At $50 \mathrm{mg} / 100 \mathrm{ml}$ most individuals are adversely affected, but not until about $80 \mathrm{mg} 100 \mathrm{ml}$ is every driver more likely to have an accident than if he had taken very little alcohol or no alcohol at all. Secondly, the rate of absorption and elimination of alcohol varies considerably, not only between different individuals but, more important, in the same individual at different times. Some countries issue a general prohibition against drinking any alcohol before driving, thereby condemning a large section of the driving population with a better than average accident record who use alcohol responsibly in association with driving. Our own Government seems quite content to spend large sums of money on exhorting people not to drink and drive, overlooking the fact that such advice is unrealistic and that motivational messages of this kind are known to be largely ineffective. Considerable interest was therefore expressed at Melbourne in the compromise BMA solution introduced in 1967 together with the Road Safety Act as the "Rule of Three." So it is unfortunate that the Blennerhassett Committee chose to take the reactionary view that the only safe advice to give the public was "Don't Drink and Drive."
The lesson to be learnt from Melbourne was that further research needs to be done in Britain before really effective measures can be introduced. High on the list should come roadside surveys (similar to those carried out in other countries) of the distribution of alcohol in the driving populationnow made much easier by advances in breath testing devicescombined with surveys of the attitude of drivers towards drinking and driving. More needs to be known about drivers convicted so that the courts can adopt a more selective policy in sentencing. Finally, the Government should devise a programme similar to that of 1967 , when the introduction of the $80 \mathrm{mg}$ concentration and a screening breath test were combined with a concentrated campaign of public education. This implies repeated stepping up of the level of enforcement, at present extremely low, combined with suitable propaganda. It worked before and there is no reason to suppose that it will not work again.

'Lancet, 1907, 1, 1031.

2 Alcohol and Road Accidents: Blood Alcohol Level in Fatalities, leaflet LF634. Crowthorne, Berkshire, Transport and Road Research Laboratory, 1977.

${ }^{3}$ World Health Organisation, World Health Statistics Anmual, vol 1, Vital Statistics and Causes of Death. Geneva, World Health Organisation, 1975.

4 Ross, H L, fournal of Legal Studies, 1973, 2, 1.

-Alcohol, Drugs and Driving. Law Reform Commission Report No 4. Canberra, Australian Government Publishing Service, 1976.

'Department of the Environment, Drinking and Driving, Report of the Departmental Committee. London, HMSO, 1976.

Klein, D, Human Factors, 1976, 18, 211.

* Borkenstein, R F, An Overvieze of the Problem of Alcohol, Drugs and Traffic Safety, Presidential Address, Seventh International Conference on Alcohol, Drugs and Traffic Safety, Melbourne, 23-28 January, 1977.

${ }^{9}$ Road Safety Committee Paper 1.17. Wellington, NZ, Government Printer, 1976.

1" The Medico-Legal Investigation of the Drinking Driver. Report of a Special Committee of the British Medical Association, p 36. London, BMA, 1965.

1 Sivedish Government Committee to Review Legislation on Driving Under the Influence of Alcohol (SOU 1970:61), summary para 19, p 360. Stockholm, 1970.

12 Glatt, M M, Proceedings of the Third International Conference on Alcohol and Road Traffic, London, September 1962, p 99. London.

\section{Glasgow in July}

Perhaps it is appropriate that the BMA should be visiting Scotland in 1977, when devolution has been so much to the fore. The Representative Body last crossed the border in 1969 and those who visited Aberdeen for that annual meeting will recall the friendly courtesy and excellent hospitality of their hosts. This year Glasgow doctors will, no doubt, be doing their utmost to reinforce those pleasant memories. This is the first integrated annual meeting to be held outside London (see programme at $p$ 728). The four craft conferences will be meeting during Monday and Tuesday, 18 and 19 July. The Annual Representative Meeting will start on the Wednesday morning and, with a break that afternoon for some scientific medicine, continue until Saturday morning. This working timetable will test the political stamina of representatives and staff alike.

The evening programme, which opens with the LMC conference dinner on Monday and ends with a joint university BMA reception on Friday after Sir Ferguson Anderson's presidential address, will be an equally searching test of their social stamina. The city has one of the BMA's most active regional offices, with a thriving club for the ladies. So it is no surprise that the ladies are being offered a wide choice of excursions both in Glasgow and to the countryside around. Viewed from every angle, the prospect is inviting-whatever the fate of the devolution legislation by July. 